\title{
Development of a Low-Cost, Compact, and Portable Experimental Kit for Online Engineering Statics Course
}

\section{Dr. Md Rashedul Hasan Sarker, University of Indianapolis}

Md Rashedul H Sarker is an Assistant Professor at R.B. Annis School of Engineering at the University of Indianapolis (UIndy). Prior to joining at UIndy, he worked as a lecturer at The University of Texas at El Paso (UTEP). He also earned his Ph.D. at UTEP. His teaching and research interests include active learning, project-based learning, energy harvesting, and developing sensors using multi-functional materials

\section{Dr. Najmus Saqib, University of Indianapolis}

Najmus Saqib is an Assistant Professor in the R.B. Annis School of Engineering at the University of Indianapolis (UIndy). Saqib received his Ph.D. in Mechanical Engineering from Colorado School of Mines (CSM), focusing on "Optical Diagnostics of Lithium-Sulfur and Lithium-Ion Battery Electrolytes using Attenuated Total Reflection Infrared Spectroscopy". He likes to use innovative pedagogical techniques to facilitate student learning.

\section{Dr. George D. Ricco, University of Indianapolis}

George D. Ricco is an assistant professor of engineering and first-year engineering coordinator at the University of Indianapolis. He focuses his work between teaching the first two years of introductory engineering and engineering design and research in student progression. Previously, he was a special title series assistant professor in electrical engineering at the University of Kentucky, and the KEEN Program Coordinator at Gonzaga University in the School of Engineering and Applied Science. He completed his doctorate in engineering education from Purdue University's School of Engineering Education. Previously, he received an M.S. in earth and planetary sciences studying geospatial imaging, and an M.S. in physics studying high-pressure, high-temperature FT-IR spectroscopy in heavy water, both from the University of California, Santa Cruz. He holds a B.S.E. in engineering physics with a concentration in electrical engineering from Case Western Reserve University. His academic interests include longitudinal analysis, visualization, semantics, team formation, gender issues, existential phenomenology, and lagomorph physiology.

\section{Dr. Megan Hammond, University of Indianapolis}

Megan Hammond received her Ph.D. in Industrial Engineering from Western Michigan University. She is an assistant professor in the R.B. Annis School of Engineering at the University of Indianapolis. Her research interests include cluster analysis, anomaly detection, human centered design, and engineering education.

\section{Mr. Alexander Quinn Ruble, University of Indianapolis}

I am a junior studying mechanical engineering at the R.B. Annis School of Engineering at the University of Indianapolis. I like researching additive manufacturing as well as new forms of education for engineers.

Mr. Bill Faton, University of Indianapolis

I am a junior studying Mechanical Engineering at the University of Indianapolis. I have interests in coding, additive manufacturing, and engineering education.

\section{Mr. James T. Emery II, University of Indianapolis}

James Emery is the Laboratory Manager for Mechanical Systems at the R.B. Annis School of Engineering at the University of Indianapolis. Prior to coming to the University of Indianapolis James worked as a lead model maker at a scale model wind tunnel.

\section{Dr. Kenneth Reid, University of Indianapolis}




\section{ASEE ANNUAL CONFERENCE \\ Virtual Meeting | July 26-29, 2021 | Pacific Daylight Time

Kenneth Reid is the Associate Dean and Director of the R.B. Annis School of Engineering at the University of Indianapolis and an affiliate Associate Professor in Engineering Education at Virginia Tech. $\mathrm{He}$ is active in engineering within K-12, serving on the TSA Board of Directors. He and his coauthors were awarded the William Elgin Wickenden award for 2014, recognizing the best paper in the Journal of Engineering Education. He was awarded an IEEE-USA Professional Achievement Award in 2013 for designing the nation's first BS degree in Engineering Education. He was named NETI Faculty Fellow for 2013-2014, and the Herbert F. Alter Chair of Engineering (Ohio Northern University) in 2010. His research interests include success in first-year engineering, engineering in K-12, introducing entrepreneurship into engineering, and international service and engineering. He has written texts in design, general engineering and digital electronics, including the text used by Project Lead the Way. 


\title{
Development of a low-cost, compact, and portable experimental kit for online engineering statics courses (Work in Progress)
}

\begin{abstract}
Online education is expanding rapidly. The ongoing COVID-19 pandemic has forced many universities to move from conventional, face-to-face instruction to hybrid or entirely online instruction. To overcome this unprecedented situation, instructors have modified course content and laboratories to be available virtually while trying to make them as interactive as possible. Virtual laboratories are either mostly pre-recorded experiments or involve controlling physical/virtual equipment through an online interface. None of these methods provide an adequate hands-on learning experience, which is essential for understanding fundamental engineering concepts. For online and distance learning programs, hands-on activities in a laboratory classroom setting are not always feasible, generating a strong push to develop lowcost, compact, and portable experimental toolboxes and kits that individual students can obtain. A group of faculty, students, and staff at the University of Indianapolis has developed an experimental toolbox that allows students to visualize engineering statics fundamentals. The experimental kit and a list of experiments complete with instructions will be made available to the students at the beginning of the course to perform the laboratory-style experiments at home. Students will be able to collect an experimental kit from campus with an appropriate deposit (each kit costs approximately \$180 to \$200 US). The university can also ship kits to students' addresses upon request with an additional delivery cost. Students can return the experimental kit at the end of the course and have their deposits returned. Performing laboratory style experiments at home using these kits will provide a valuable hands-on learning experience.
\end{abstract}

\section{Introduction:}

Originally, the main thrust for this work lied in the fundamental assumption that hands on experiences universally lead to greater student outcomes in introductory mechanical engineering courses [1]. We operated under parameters set forth by Benson [2], Dollár [3, 4], and others that even under the best of circumstances, online curriculum are usually a substitute or at least a mild 
panacea for in-person, kinesthetic activities [5]. Of major importance to many of these works is the persistence of the dreaded if students simply engaged in more "real engineering" thought monster that arises as a panacea any time the community embarks upon a journey of self-analysis and reinvention. This of course is not an ubiquitous truth, and is fraught with exceptions. The primary counter-argument to the tug of war encompassing real engineering is that while many works assume students will naturally have greater outcomes when their interests are engaged, what happens when this house of cards collapses?

The times and situation we currently inhabit have radically changed over the past year, and this has forced us to reflect upon how our apparatus will affect student outcomes when the social development of our apprentice engineers does not include the typical college experience, forgoes regular lab instruction, and reinforces different cognitive pathways and habits. Within this world, the sociological and social psychology notion of zero acquaintance takes on new and more powerful meaning [6]. Just as with Vygotsky's premise of changing cognitive pathways being initiated by a major revolution or other cultural phenomenon, our approach to providing a portable, at-home apparatus for introductory statics cuts two ways [7]. First, this setup becomes a key step in bridging the gap between the traditional lab's in-person experience and potential athome or remote experiences. In today's post-COVID world, a viable lab setup can help maintain continuity of lab work over an extended period of time. Second, as students entering their major courses have not yet been exposed to real engineering yet, this apparatus helps us provide a normalizing factor that will make the eventual transition back to normalcy in the classroom less abrasive. One such problem at hand is the risk of normalizing procrastination due to extended online or at-home learning [8]. When the actual, real setup used in the classroom is now available at home, it potentially attenuates this phenomenon. This also removes one of the main barriers studied in earlier online learning theories created when students or faculty are thrust into a new virtual space - one mimicked by when entire universities are compelled to close shoppe abruptly and go virtual [9].

We adopted the idea - and still maintain this notion - that a nuanced and iterative approach to bolster student proclivity with introductory lab equipment is a viable and effective way of increasing student outcomes in mechanical engineering. This hybrid approach has the potential to not only bolster student outcomes, but provide much needed grounding for students during 
this unstable and uncertain period in higher education. The seminal education researcher Astin has been known for promoting the idea that the most important data point in the study of higher education is the institution itself [10], but we are not in normal times. In times of mass change, the way through can be a return to fundamental concepts taught with the most effective means at hand. We aim to empower faculty to ground students and provide stability through this work.

\section{Development of the portable experimental kit:}

A work panel is an essential piece of equipment in an engineering statics-teaching laboratory. Sarker et al. [11] previously developed a work panel made with aluminum plates and aluminum extrusion frames. It was envisioned for use in a lab classroom setup. In light of the COVID-19 pandemic, a low-cost, compact, and portable experimental kit for online engineering statics courses was developed. Preparing the kit requires the construction of a lightweight work panel, collecting all of the necessary tools, and demonstrating experiments typically covered in an engineering statics course. Students will acquire this kit at the beginning of the course and return it at the end of the course, which can then be redistributed to students enrolled in subsequent offerings of the course. The students will be required to make a deposit equivalent to the total cost of the kit, which will be returned upon returning the kit. The per-unit cost of the experimental kit has not yet been fully determined as only one prototype has been constructed. However, it is expected to cost between $\$ 180$ to $\$ 200$ US.

All the materials were purchased locally. The machine shop at the University of Indianapolis was used as needed. A lightweight work panel was constructed similar to the one reported previously by Sarker et al. [11] but using plexiglass instead of aluminum for a lower cost, without compromising any functionality. Figures 1 and 2 show the work panel. The work panel is easy to assemble, and it can be folded flat to ship inside a cardboard box. 

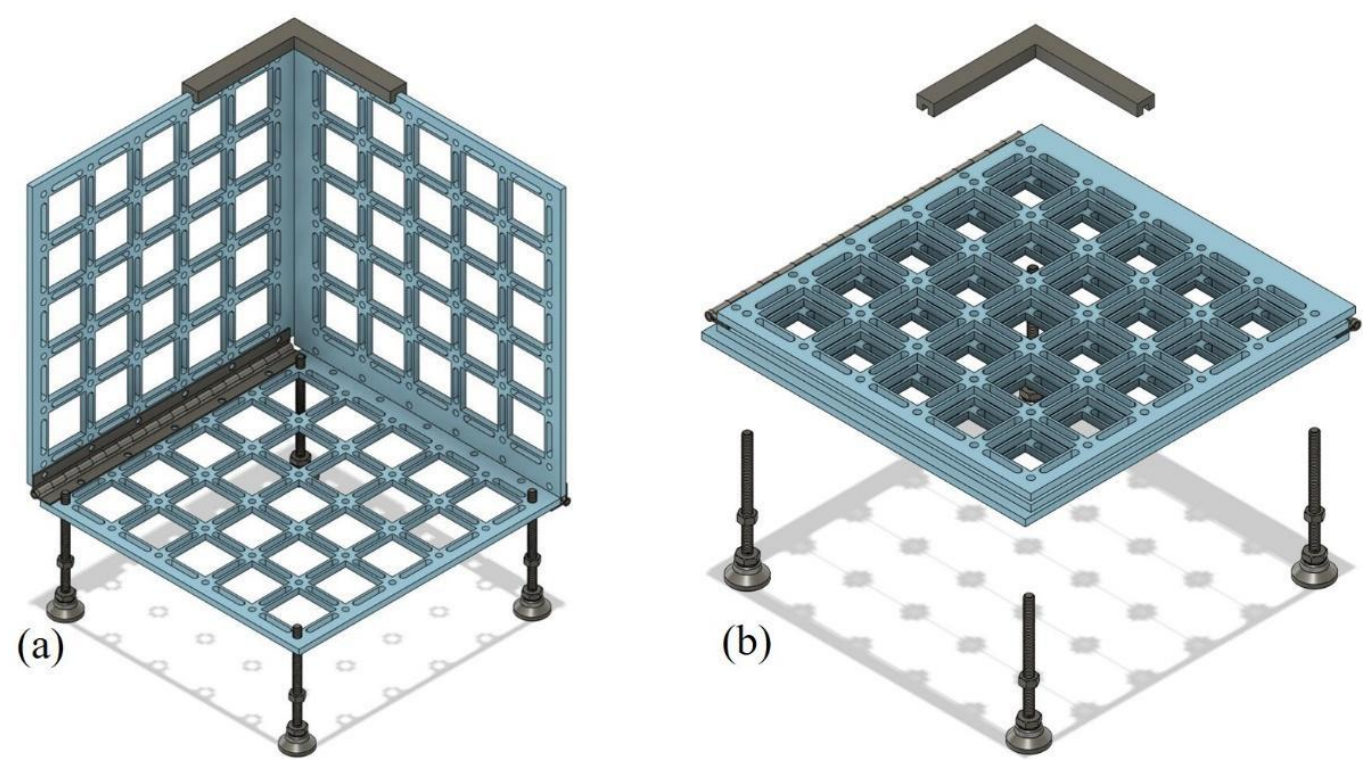

Figure 1: Model of (a) a fully assembled work panel, and (b) a folded work panel.
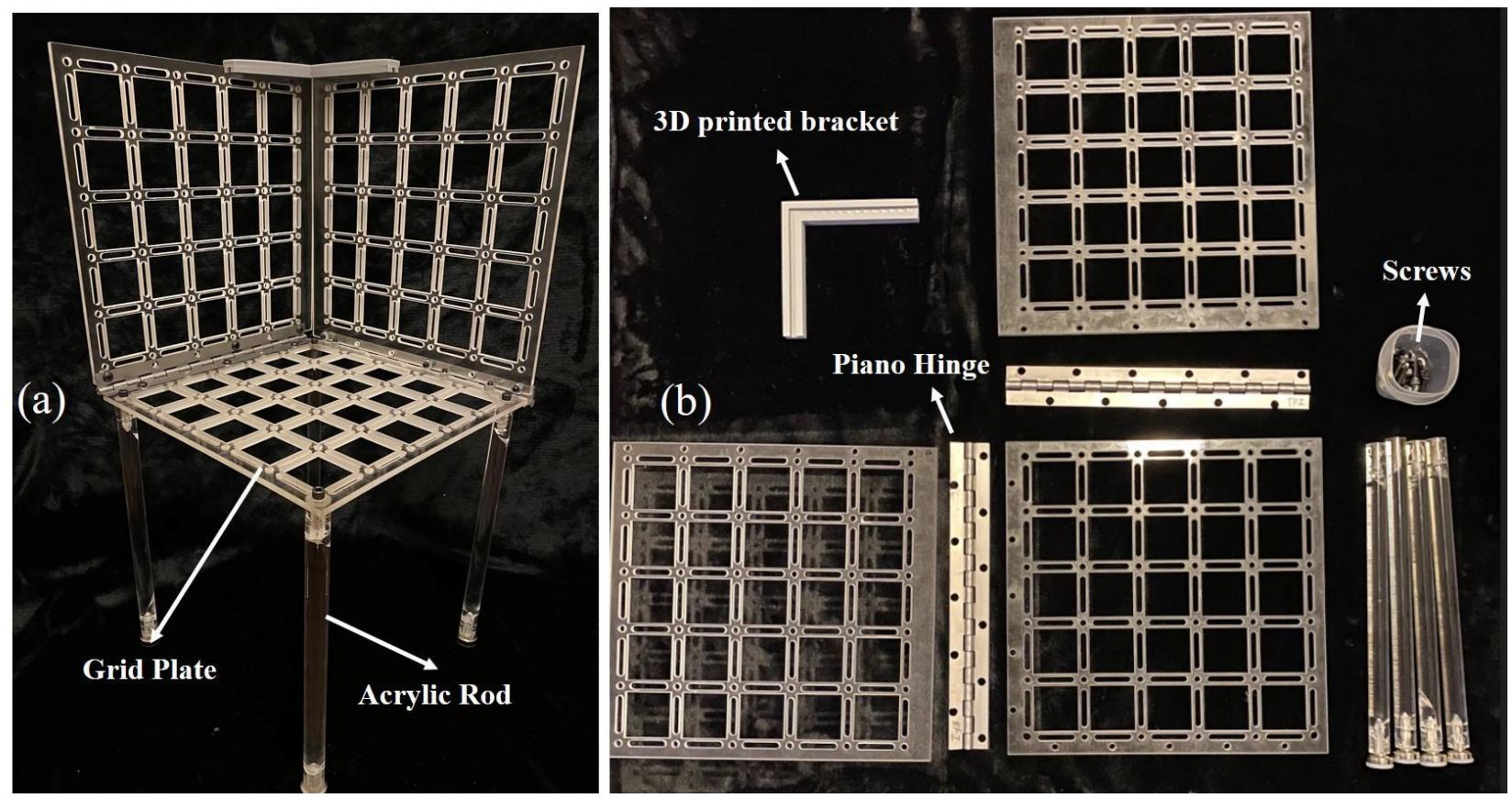

Figure 2: (a) A Fully assembled work panel, and (b) a disassembled work panel.

In this lighter version of the work panel, various add-on tools, including pulleys, clamps, cords, weights, and weight hangers, can be used to demonstrate statics experiments in two and threedimensional spaces. 
The following experiments were demonstrated using the proposed kit:

1. Force equilibrium in two-dimensional spaces

2. Force equilibrium in three-dimensional spaces

3. Demonstration of a vector dot product

4. Demonstration of vector cross product

5. Beam reactions

6. Center of gravity of an area and volume

7. A spaghetti bridge construction project

Sarker et al. [11] presented some of the experiments listed above (2, 3, and 4). The remaining experiments have not yet been used within a course. The work panel is not limited to the experiments mentioned above; it is highly customizable and it is feasible to create many other engineering mechanics-related experiments with appropriate add-on tools. The three grid plates of the work panel were made from 0.25 " thick, 12 " x 12 " plexiglass sheets using a water jet cutter. These plates can also be manufactured with other materials, such as plywood sheets, and cut using a laser cutter. The grid plates were connected by tight-clearance piano hinges, a 3D printed Lshaped PLA polymer bracket, and four 0.25 " diameter by 12 " long acrylic rods. It should be noted that the acrylic rods are fairly brittle and an alternative material for these components is currently being investigated.

\section{Force equilibrium in two-dimensional spaces}

The work panel was used to demonstrate a force equilibrium in two-dimensional spaces, as shown in Figure 3. Either of the vertical panels can be used as to mount the add-on tools, including pulleys, keyrings, twine, weight hangers, and weights. Students can sum all forces to zero to determine any unknown resultant forces. 

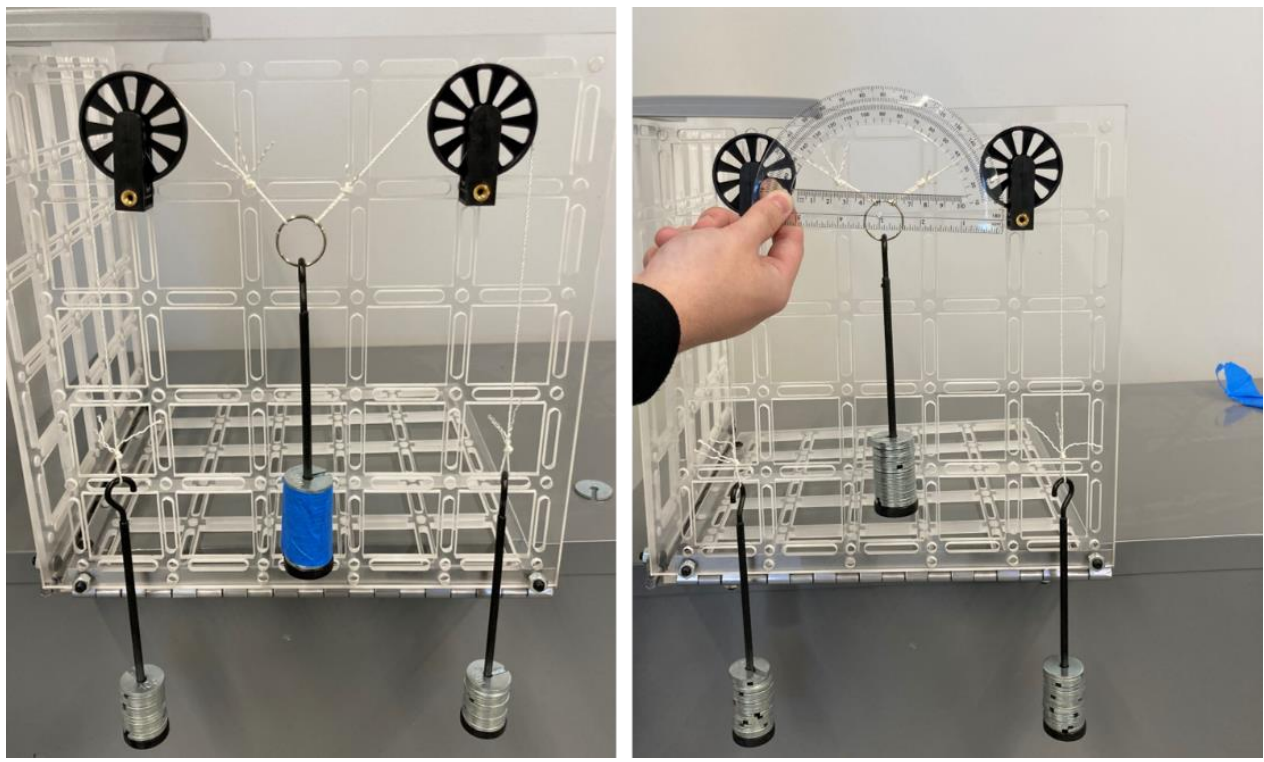

Figure 3: Demonstration of force equilibrium in two-dimensional spaces.

\section{Force equilibrium in three-dimensional spaces}

The demonstration of a force equilibrium in three-dimensional spaces is shown in Figures 4 and 5. Figure 4 shows a typical textbook exercise problem in this topic, which was reconstructed with the kit using pulleys, cords, weight hangers, and weights attached to the work panel (Figure 5).

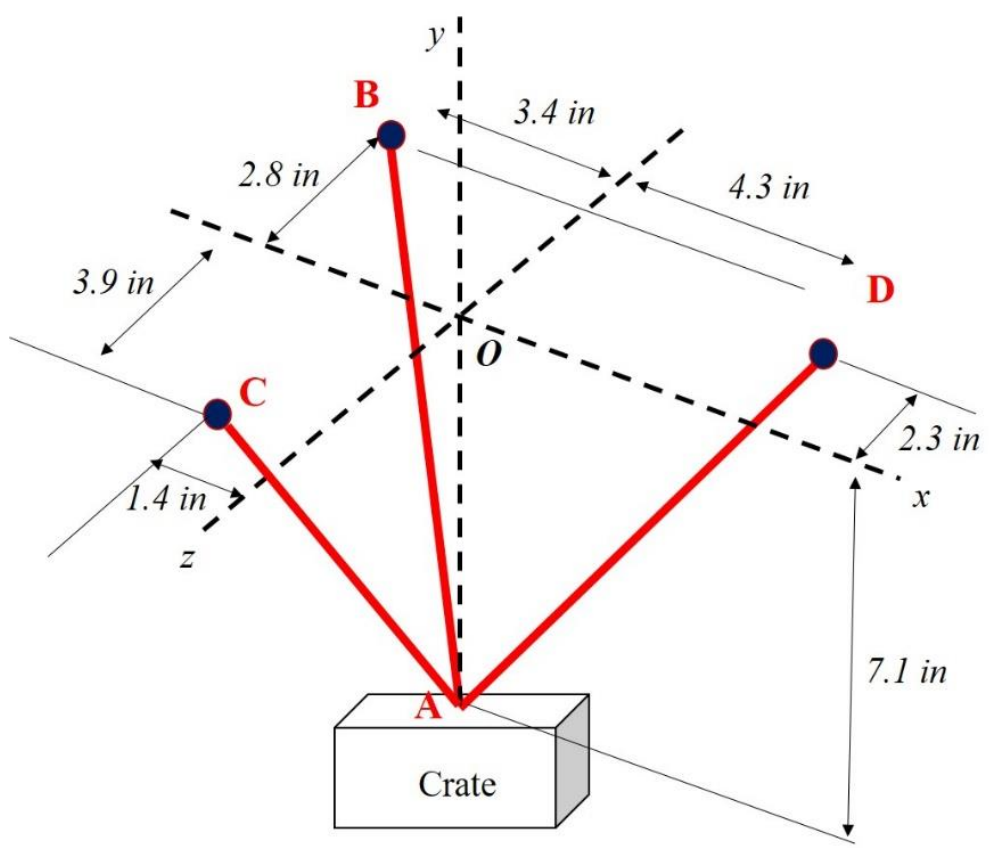

Figure 4: A sample problem to demonstrate force equilibrium in three-dimensional spaces. 

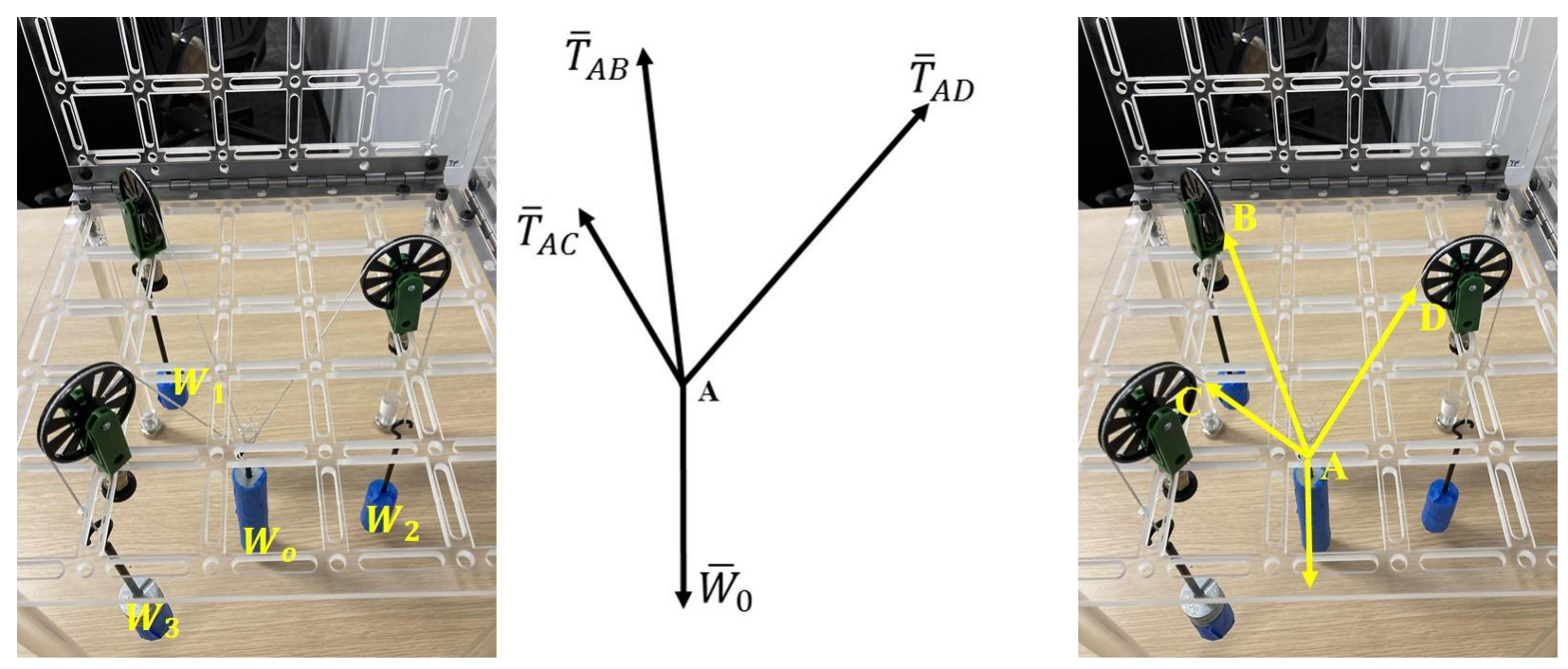

Figure 5: Reconstruction of the sample problem presented in Figure 4 using the work panel with the corresponding free-body diagram.

This demonstration uses three weight hangers $\left(W_{1}, W_{2}\right.$, and $\left.W_{3}\right)$ to balance the fourth one $\left(W_{0}\right)$ using twine and low friction pulleys. Two weights $\left(W_{1}\right.$, and $\left.W_{2}\right)$ and a center weight $\left(W_{0}\right)$ are fully covered with painter's tape to represent unknown tensions on the two cables and the unknown weight of the crate. One weight $\left(W_{3}\right)$ was visible to represent a known tension on one of the cables. To determine the unknown weight $\left(W_{0}\right)$ of the crate, an equilibrium condition can be applied.

Typical textbook exercise problems (such as the one shown in Figure 4) usually provide the coordinates of the points but finding the coordinates in the reconstructed setup (Figure 5) is not straightforward. At this point students may realize the difficultly of measuring angles in threedimensional spaces compared to two-dimensional spaces. An eyeball measurement of angles using a protractor will lead to large errors. Furthermore, the angle at which the cord leaves the pulley depends upon the equilibrium conditions. Therefore, to get accurate coordinates of the points, the previously published procedure is recommended [11]. 


\section{Demonstration of a vector dot product}

In engineering statics, the vector dot product determines the angle between cables in threedimensional spaces. For the hands-on activity, one sample configuration of cable attachments on the work panel is shown in Figures 6 and 7. Any point on the work panel can be selected as the origin of a Cartesian coordinate system, and the position coordinates of the points $A, B$, and $C$ can be found using a ruler scale or a measuring tape. The vector expression and magnitude of $A B$ and $A C$ can be used in a vector dot product expression to find the angle between $A B$ and $A C$. This experiment introduces an otherwise more abstract concept using visualization, which has been shown as a desirable means to improve learning [12]. A detailed explanation of this experimental procedure was previously published [11].
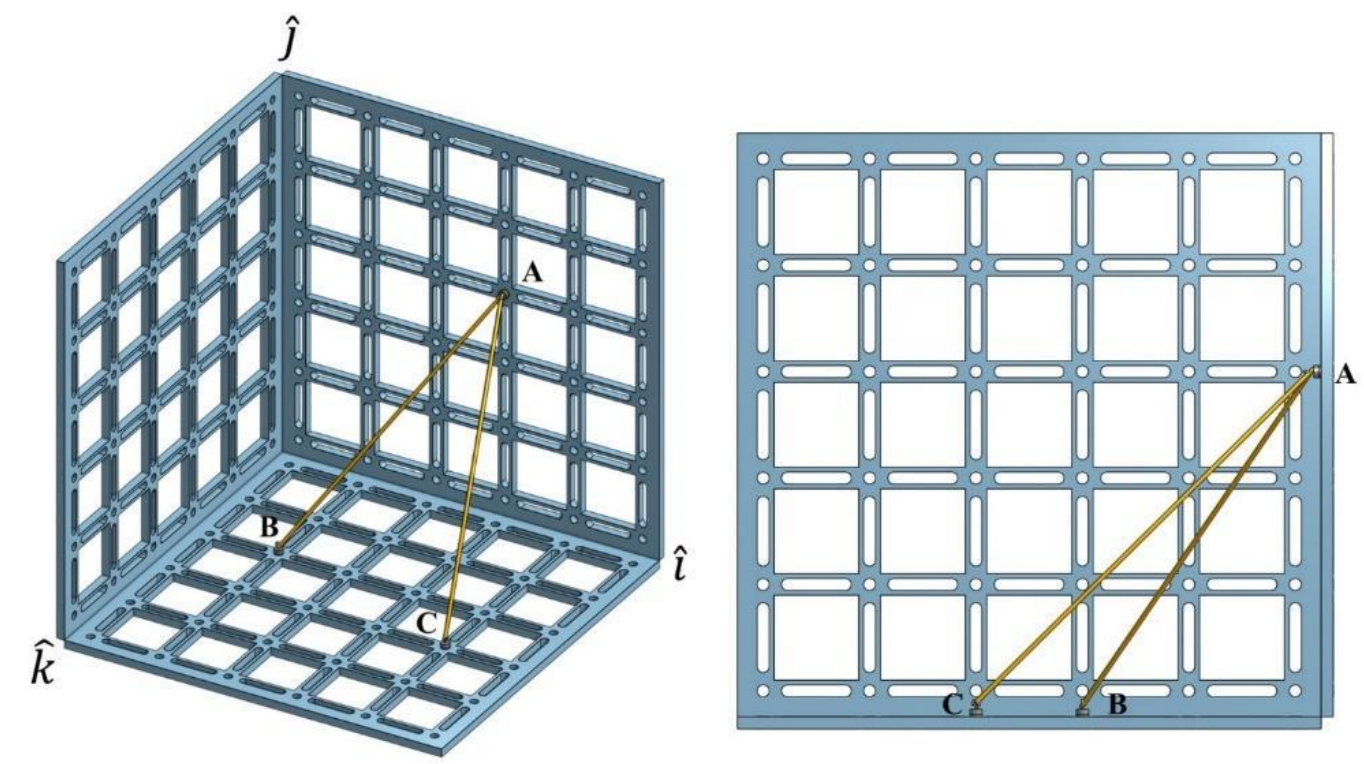

Figure 6: Two different views of a vector dot product demonstration on the work panel. 

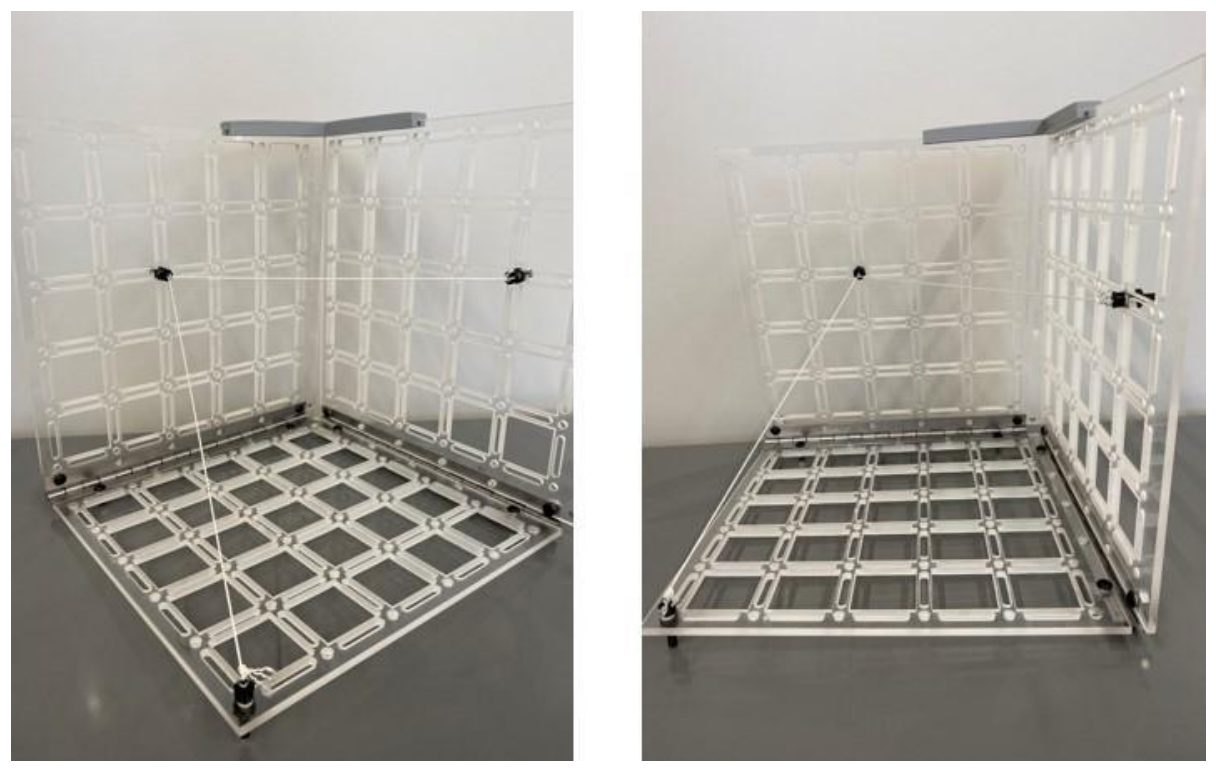

Figure 7: Demonstration of a vector dot product experiment on the work panel.

\section{Demonstration of vector cross product}

A hands-on exercise for reducing a system of forces (parallel forces) into a force-couple system was developed using digital weight scales, a transparent plexiglass sheet, weights, weight hangers, and leveling feet. Figures 8 and 9 show the demonstration of the vector cross product.
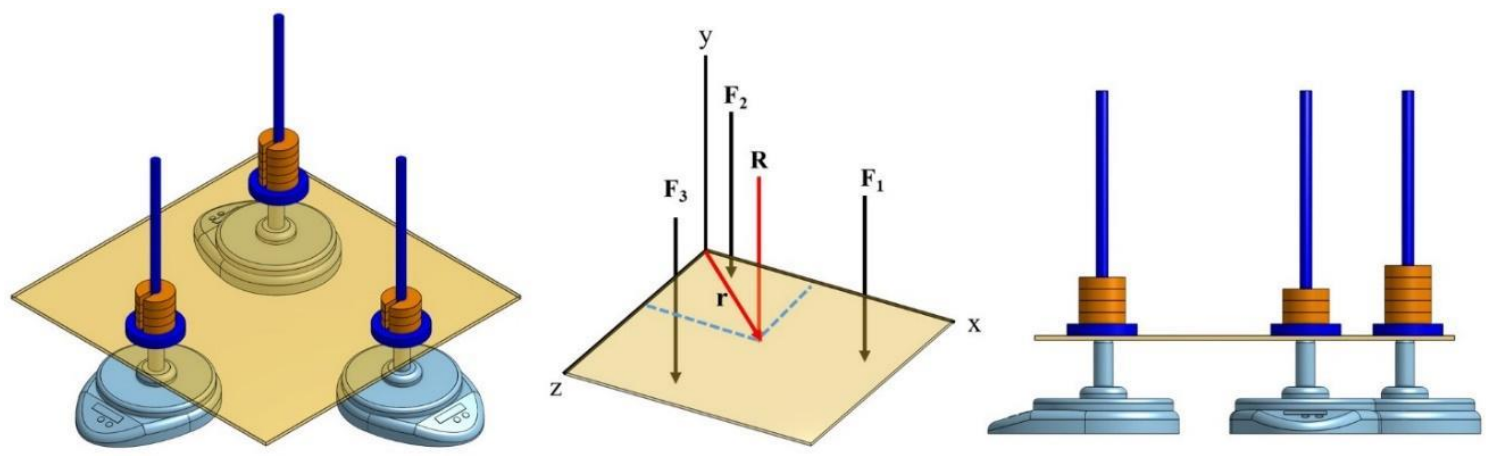

Figure 8: Schematic demonstration of vector cross product with an equivalent force-couple system. 

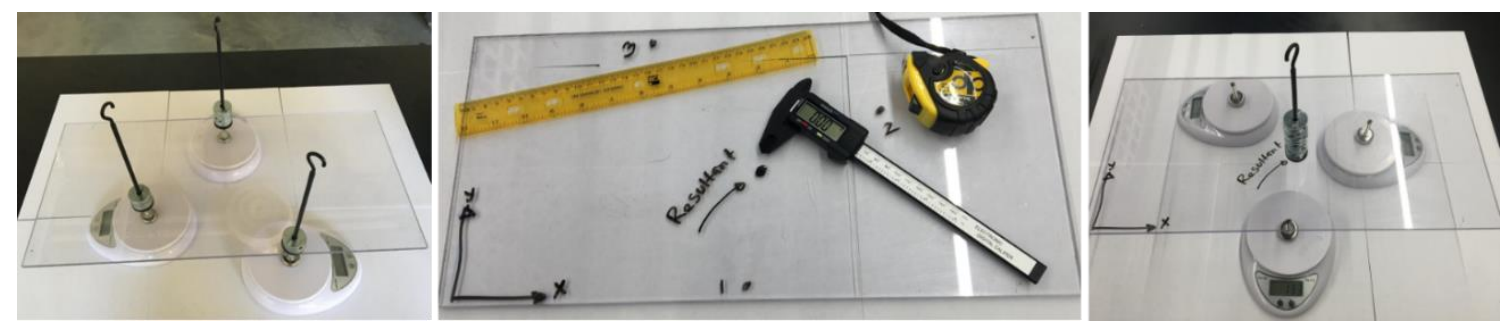

Figure 9: Demonstration of a vector cross product with an equivalent force-couple system using the experimental kit.

Three leveling feet were placed on top of the three weight scales. A transparent plexiglass sheet was then placed on top of the leveling feet. The readings of the scales were zeroed at this point. A marker was used to mark the points on top of the plexiglass, touching the leveling feet's top faces. Three weight hangers with different weights were then carefully laid on top of the marked points on the plexiglass. The corresponding reaction forces were measured using the digital scales. The readings in grams were later converted into forces. A ruler scale, measuring tape, or slide calipers can measure the coordinates of three different points where the weight hangers were placed. The origin of the coordinate system can be any point on top of the plexiglass sheet. The position vector of the resultant force was calculated by reducing the three parallel forces into a force couple system. The detailed experimental procedures of this demonstration have been previously reported [11].

\section{Beam reactions}

A simply supported beam was demonstrated to show the effect of load and moment along the beam by its reaction forces. A one-foot length of perforated square tube was used as a beam, and two leveling feet were attached at both ends. A 3D-printed angle bracket was also placed on top of the beam to apply a force moment on the beam. The beam was then placed on top of two digital weight scales, and the scale readings were zeroed at this point. Figures 10 and 11 show the demonstration of the beam's reaction forces. 

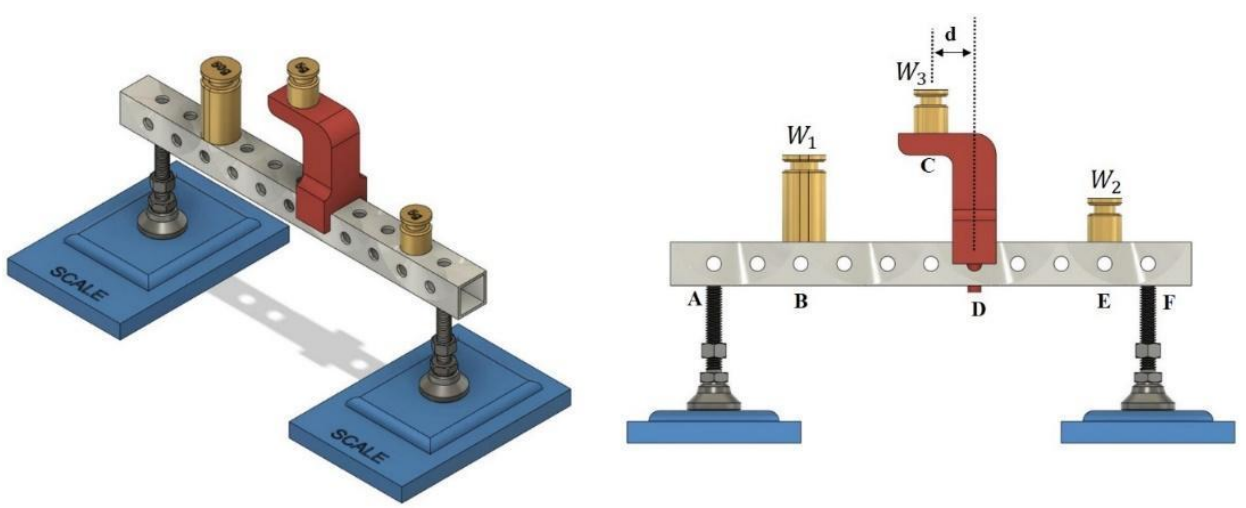

Figure 10: Schematic demonstration of beam reaction.
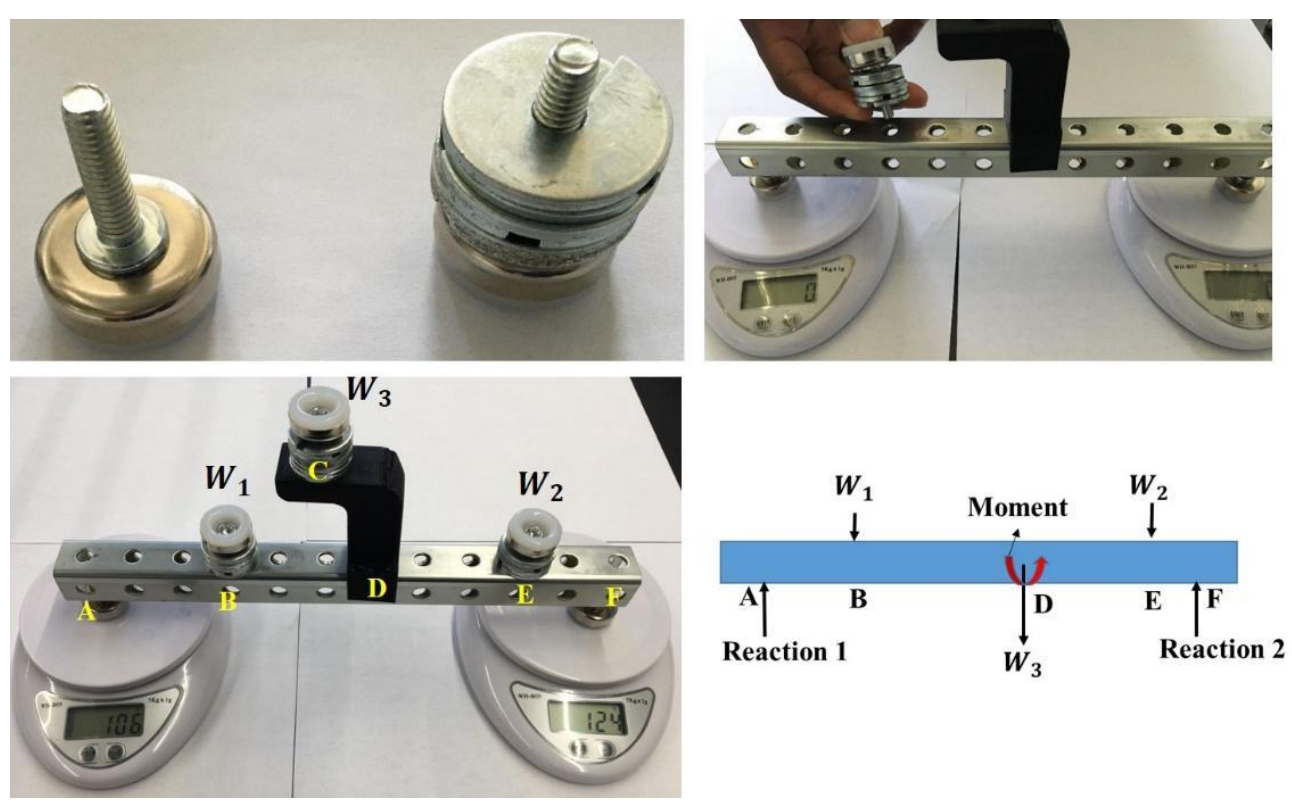

Figure 11: Demonstration of beam reaction using the kit.

The weights were attached to two more leveling feet and then placed on top of the beam. This was made to ensure the loads are applied at the center hole of the beam. A ruler scale and slide calipers were used to measure the distances between the load, reaction points, and hole diameter. Digital measuring scale readings were also recorded to compare with the analytical solution of the reaction forces of the beam. The load at point $C$ needs to be applied to point $D$ with an equivalent force and moment calculation. After interpreting the free-body diagram, the equilibrium conditions can be applied to find the reaction forces at points $\mathrm{A}$ and $\mathrm{F}$. In order to reduce the error to less than 5\% a careful measurement of positions is required. 


\section{Center of gravity of an area and volume}

To demonstrate the center of gravity of an area and volume, a 0.25 " thick plywood sheet was used to cut composite areas by a laser cutter. After making the composite areas, the leftover pieces of plywood were glued together to make different volumes. Figures 12 and 13 show the demonstration of the center of gravity for a composite area and volume, respectively.

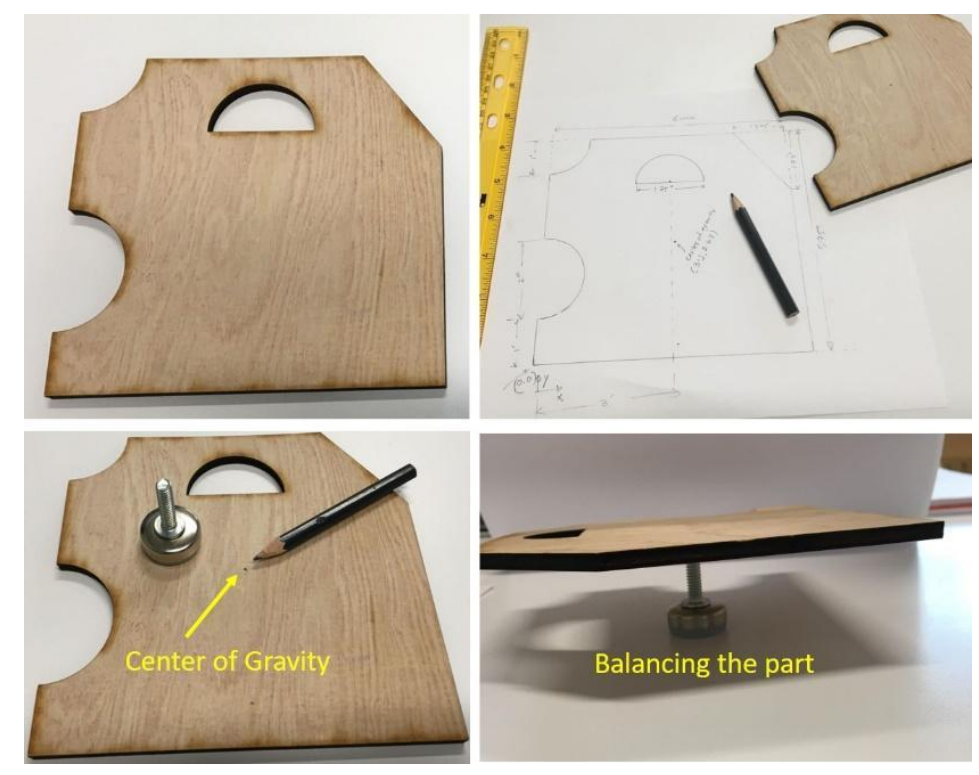

Figure 12: Demonstration of the center of gravity of a composite area.

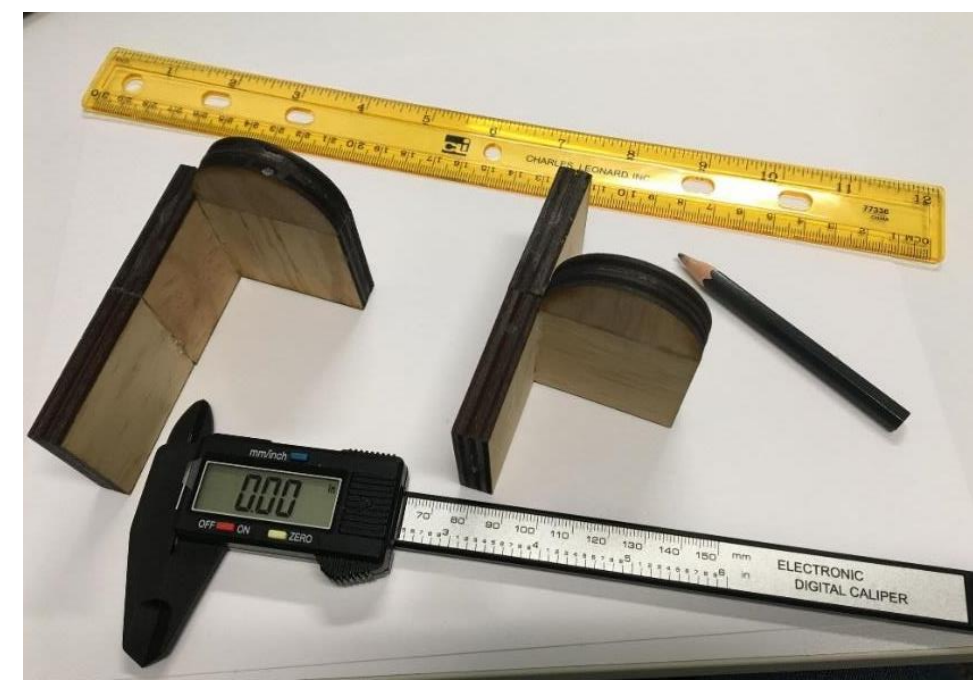

Figure 13: Demonstration of the center of gravity of composite volumes. 
To measure the dimensions of the composite areas, students can trace the parts on paper and then measure the dimensions using a ruler, slide calipers, and protractor. Students can also use any CAD software to represent the dimensions of the areas and volumes. The CAD software can also identify the centroid for areas and volumes, which can also be used to compare with the analytical solutions.

Assuming the plywood is uniform in thickness, and homogeneous, the center of gravity coincides with the centroid of its area. Also, assuming the composite volume made with plywood is homogeneous, the center of gravity coincides with the centroid of the volume.

\section{Spaghetti bridge project}

A design challenge to construct a spaghetti bridge can also be performed by students with design constraints provided and with minimum supervision. The feasibility of constructing a bridge with $1 \mathrm{lb}$ of dry spaghetti pasta was examined. It is possible to design, construct, and test a spaghetti bridge with particular design constraints, including maximum length, height, and width constraints. A glue gun can provide better bonding between the joints, but one might not be available to students, or may rise safety concerns. To avoid this, a sample spaghetti bridge was constructed using Play-Doh and white glue. The Play-Doh can be used to make the joints, and the white glue can be used to join spaghetti sticks together to create a bridge floor. It is recommended to make two trusses separately and join the two trusses while the Play-Doh is still soft and easy to form. It is also recommended to wait overnight before attaching the bridge floor with white glue. Figure 14 shows the testing of a spaghetti bridge made with both a hot glue gun and Play-Doh. 

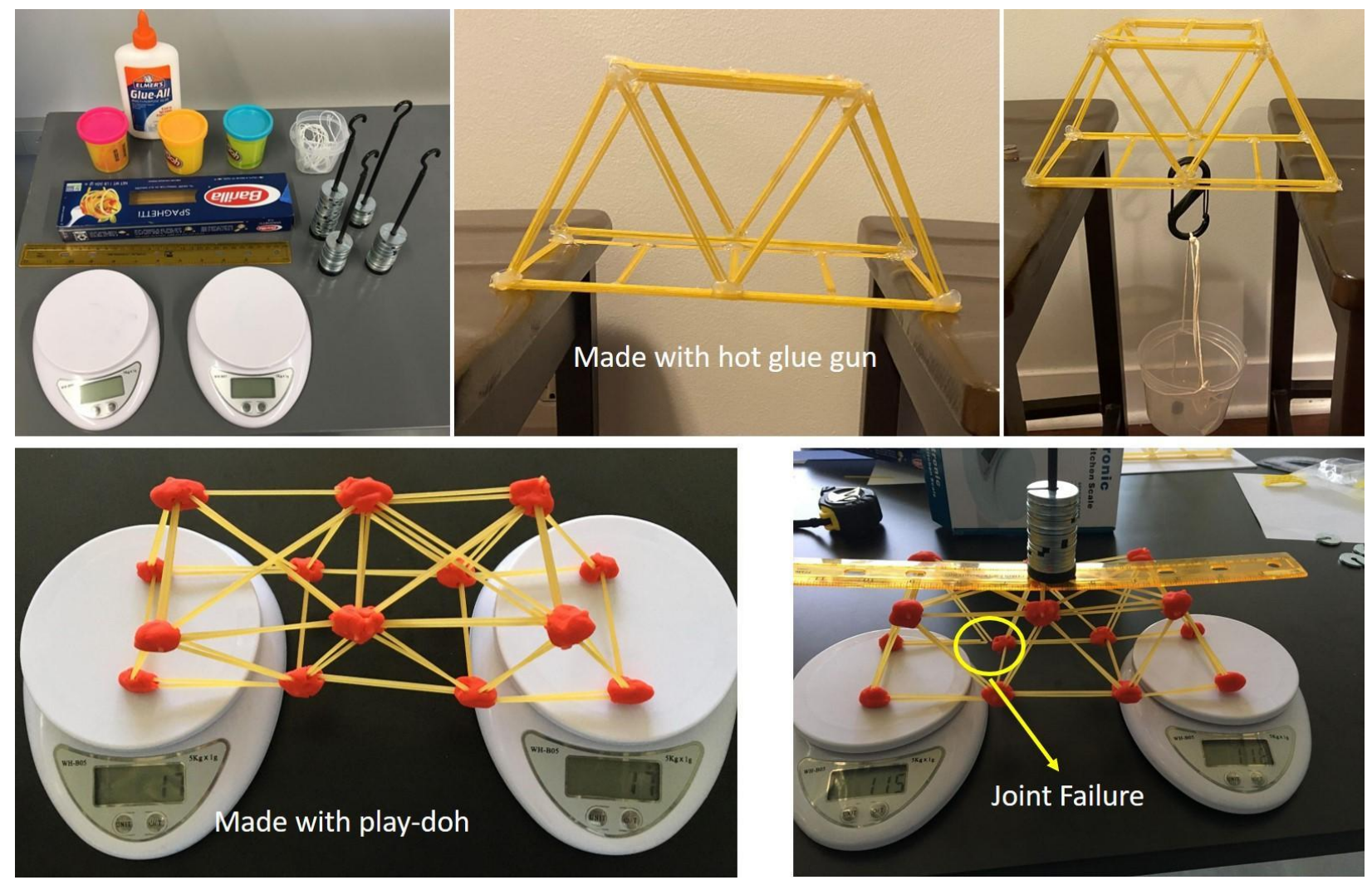

Figure 14: Demonstration of the spaghetti bridge project.

Figure 15 shows all of the contents of the kit. Each student will have access to a similar box to perform the experiments remotely with minimum supervision. Some of the consumable items need to be replaced once the students return the boxes, including a box of spaghetti, Play-Doh, white glue, twine, and batteries before future distribution. Table 1 lists of all of the materials with corresponding notes. 

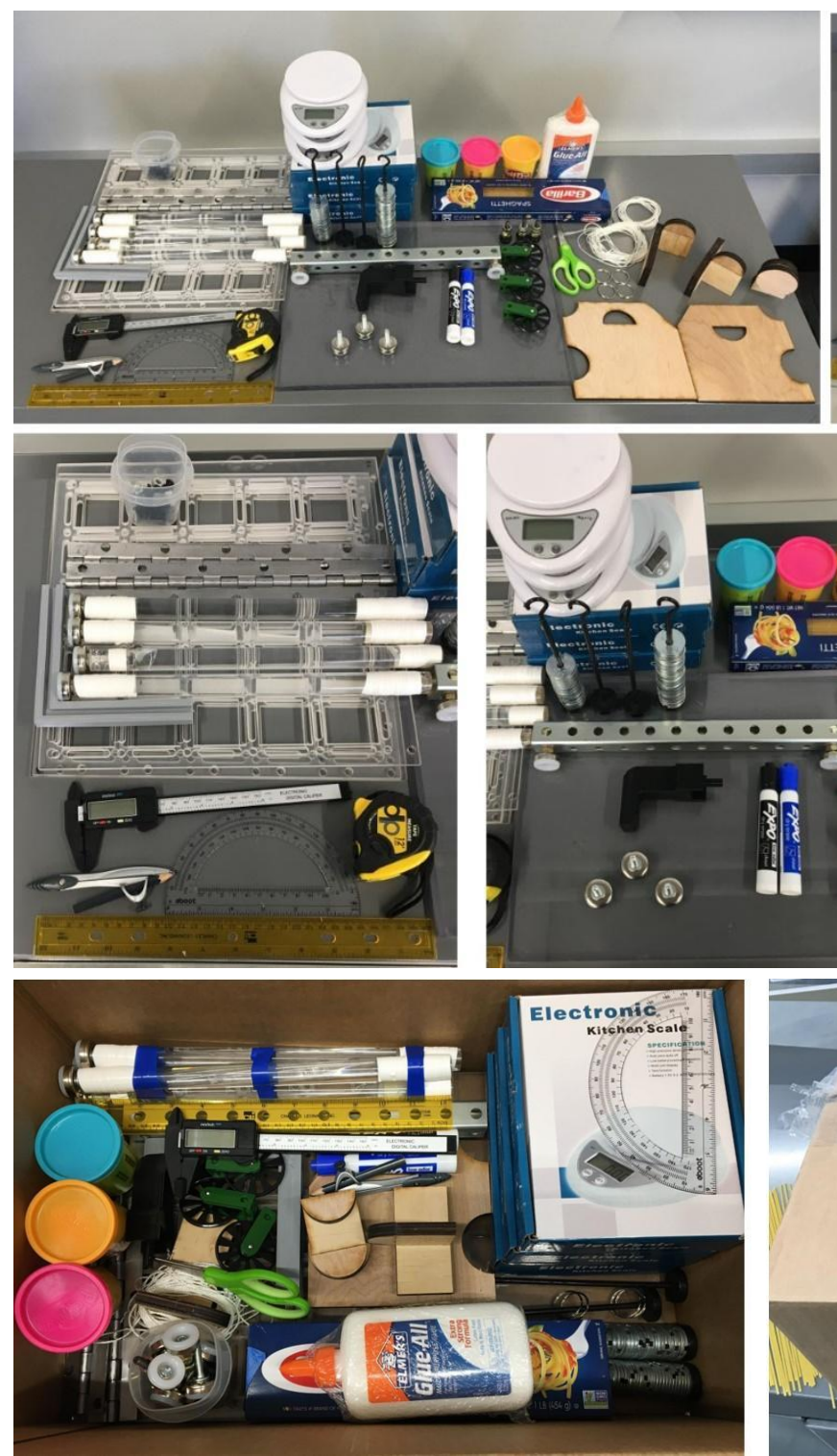
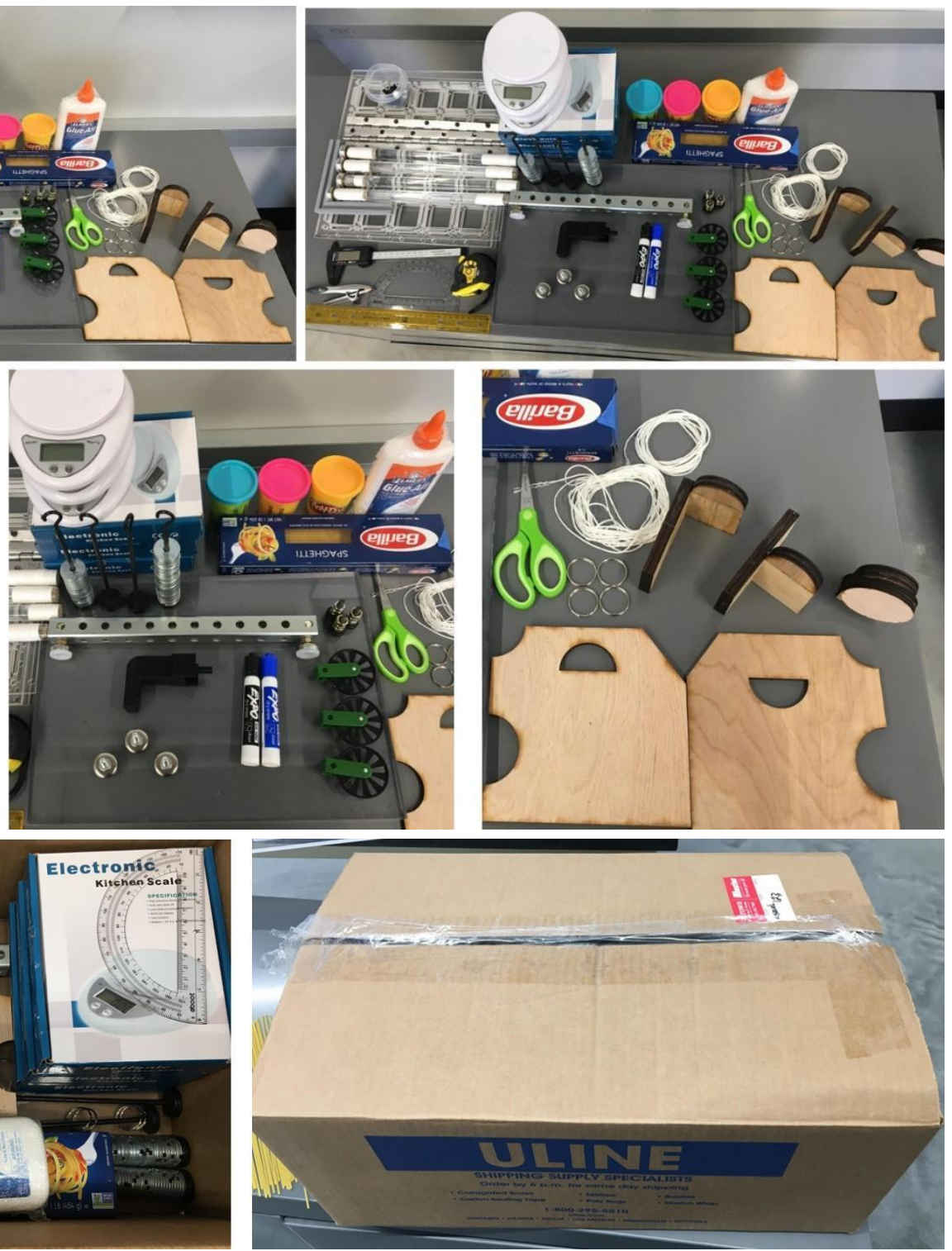

Figure 15: The contents of the experimental kit. 
Table 1: A list of materials to be included in each kit.

\begin{tabular}{|c|c|c|}
\hline \# & Item & Note \\
\hline 1 & A lightweight work panel & $\begin{array}{l}\text { The grid plates were cut from a } 0.25 \text { " thick plexiglass sheet. These } \\
\text { plates can also be made with plywood sheets and cut with a laser } \\
\text { cutter to reduce the cost. The acrylic rods are fragile and can be } \\
\text { replaced with wooden dowels. Drawings available upon request. }\end{array}$ \\
\hline 2 & 3D-printed bracket & $\begin{array}{l}\text { Printed with PLA polymer filament. This bracket holds the vertical } \\
\text { grids of the work panel. This 3D-printed part can be replaced by } \\
\text { corner braces and screws. }\end{array}$ \\
\hline 3 & Ultra-pulleys (3 pulleys) & $\begin{array}{l}\text { These low-friction ultra-pulleys are the most expensive components } \\
\text { (www.vernier.com). Super-pulleys (www.pasco.com) are also used } \\
\text { for mounting on a vertical plane (Figure } 3 \text { ) and in any other } \\
\text { inclined planes. The super-pulleys are slightly more expensive than } \\
\text { the ultra-pulleys. }\end{array}$ \\
\hline 4 & Weights and weight hangers & $\begin{array}{l}\text { These were purchased from www.tecquipment.com. The weights } \\
\text { are } 10 \mathrm{~g} \text { each. These parts can also be replaced by any other } \\
\text { weights and hangers. }\end{array}$ \\
\hline 5 & $\begin{array}{l}\text { Digital kitchen scale } \\
\text { ( } 3 \text { scales) }\end{array}$ & $\begin{array}{l}\text { LuckyStone Wh-B05 Electronic Digital Kitchen Food Scale } \\
\text { (www.amazon.com). These cost less than } 10 \mathrm{USD} / \mathrm{scale} \text { with a } \\
\text { capability to measure up to } 5 \mathrm{~kg} \text { with } 1 \mathrm{~g} \text { resolution. Any other } \\
\text { digital weight scales can also be used instead. }\end{array}$ \\
\hline 6 & Perforated square beam & Steel bolt-together framing (www.mcmaster.com). \\
\hline 7 & $\begin{array}{l}\text { 3D printed frame to apply } \\
\text { moment on the beam }\end{array}$ & $\begin{array}{l}\text { Printed with PLA polymer filament. Drawings available upon } \\
\text { request. }\end{array}$ \\
\hline 8 & $\begin{array}{l}\text { Plywood sheet to make } \\
\text { composite areas and volumes }\end{array}$ & $\begin{array}{l}\text { A } 0.25 \text { " thick plywood sheet was cut using a laser cutter to make } \\
\text { composite areas and the leftover pieces were glued together to } \\
\text { make volumes. Drawings available upon request. }\end{array}$ \\
\hline 9 & Leveling feet (10 feet) & $\begin{array}{l}\text { These are purchased from www.mcmaster.com. Four feet were } \\
\text { mounted below the acrylic legs of the work panel. The rest of the } \\
\text { feet are required to connect with the beam and apply loads. These } \\
\text { can also be replaced with any other leveling feet. }\end{array}$ \\
\hline 10 & Tape measure & \multirow{12}{*}{ Purchased locally. } \\
\hline 11 & Slide calipers & \\
\hline 12 & Protractor & \\
\hline 13 & Ruler (1') & \\
\hline 14 & Twine & \\
\hline 15 & Scissors & \\
\hline 16 & Keyrings & \\
\hline 17 & $\begin{array}{l}\text { A transparent plexiglass }(16 " x \\
12 ")\end{array}$ & \\
\hline 18 & Marker & \\
\hline 19 & 1 lb spaghetti box & \\
\hline 20 & Play-Doh & \\
\hline 21 & White glue & \\
\hline
\end{tabular}




\section{Method}

To assess the impact of the at home lab kits on virtual student learning, the team will be comparing student understanding with the kit in a virtual learning environment to student understanding with equipment in a traditional lab setting. During the Statics course, which the kit has been designed to support material coverage, we will adopt a hybrid lab schedule. This will create opportunities for students to learn in both the non-traditional virtual environment and the university's Statics lab.

Due to smaller class sizes, our courses typically do not exceed one section of Statics offered per semester. This presents a situation that virtual and in-person learning evaluation be conducted within the same and only course section. We can examine the efficacy of the at home kit through multi week lab topics and performance collection. Consecutive labs covering topics of which the at home kit supports instruction and learning (i.e. force equilibrium in threedimensional spaces and demonstrations of a vector dot product) will be offered to directly compare student comprehension of the material via the low-cost kit and specialized university lab equipment. One portion of the multi week lab will be covered with the at home kits and limited virtual instructor interaction (e.g. virtually communicated questions and answers), while students are either off campus or in a simulated virtual environment such as multiple work rooms with kits and personal laptops. The other portion of the multi week lab will consist of a traditional lab setting with sophisticated equipment and ample instructor interaction typically available during such lab settings.

Performances in the virtual and in-person lab environments will be captured through lab assignments and student reflections. Contingent on the ability to assemble enough kits for the statics lab over the summer months, this assessment will be conducted during the next academic year.

\section{Conclusion:}

A low-cost, compact, and portable experimental kit for online engineering statics courses has been developed. The kit will bolster student proclivity with introductory lab equipment, which is a viable and effective way of rising student outcomes in mechanical engineering. Next, the kit will be distributed to students and its efficacy on student outcome attainment will be assessed. 


\section{References:}

[1] B. Coller, "An experiment in hands-on learning in engineering mechanics: Statics," International Journal of Engineering Education, vol. 24, 01/01 2008.

[2] L. Benson, S. Biggers, W. Moss, M. Ohland, M. Orr, and S. Schiff, "AC 2007-1563: ADAPTING AND IMPLEMENTING THE SCALE-UP APPROACH IN STATICS, DYNAMICS, AND MULTIVARIATE CALCULUS," age, vol. 12, p. 1, 2007.

[3] A. Dollár and P. S. Steif, "Learning modules for the statics classroom," in Proceedings of the 2003 American Society for Engineering Education Annual Conference \& Exposition, Nashville, 2003.

[4] A. Dollar and P. Steif, "An interactive, cognitively informed, web-based statics course," International Journal of Engineering Education, vol. 24, no. 6, p. 1229, 2008.

[5] O. Pierrakos, M. Borrego, and J. Lo, "Empirical evidence to support interdisciplinary projects in engineering design experiences," in Proceedings of the 2007 AaeE Conference, 2007: Citeseer.

[6] M. J. Levesque and D. A. Kenny, "Accuracy of behavioral predictions at zero acquaintance: A social relations analysis," Journal of Personality and Social Psychology, vol. 65, no. 6, p. 1178, 1993.

[7] S. Newman, "Thought and Language. Studies in Communication," ed: JSTOR, 1963.

[8] N. Michinov, S. Brunot, O. Le Bohec, J. Juhel, and M. Delaval, "Procrastination, participation, and performance in online learning environments," Computers \& Education, vol. 56, no. 1, pp. 243-252, 2011.

[9] M. Christie and R. G. Jurado, "Barriers to innovation in online pedagogy," European Journal of Engineering Education, vol. 34, no. 3, pp. 273-279, 2009.

[10] A. W. Astin, "How "good" is your institution's retention rate?," Research in higher education, vol. 38, no. 6, pp. 647-658, 1997.

[11] M. R. Sarker, N. Saqib, G. Ricco, M. Hammond, J. Hilt, and J. Emery, "WIP: Hands-on Engineering Mechanics with a Three-dimensional Laboratory Unit," Virtual On line, 2020/06/22, Available: https://peer.asee.org/35542

[12] D. Bairaktarova, D. Williams, and P. Katsioloudis, "Analysis of Blended and Multi-modal Instruction and its Effects on Spatial Visualization Ability," The Engineering Design Graphics Journal, vol. 83, 2019. 